\title{
Applying Electronic Medical Records in health care
}

\section{Physicians' perspective}

Mohammadhiwa Abdekhoda ${ }^{1,2}$; Maryam Ahmadi ${ }^{3,4}$; Afsaneh Dehnad ${ }^{5}$; Alireza Noruzi6; Mahmodreza Gohari ${ }^{5}$

${ }^{1}$ School of health management and medical informatics. Tabriz University of medical sciences. Tabriz, Iran; ${ }^{2}$ Iranian Center of Excellence in Health Management (IceHM). School of Management and Medical Informatics. Tabriz University of Medical Sciences, Tabriz, Iran; ${ }^{3}$ Department of Health Information Management, School of Management and Medical Information science, Iran University of Medical Science, Tehran, Iran; ${ }^{4}$ Health Management and economics Research Center, School of health Management and information. Iran University of Medical Sciences, Tehran, Iran; ${ }^{5}$ School of Management and Medical Information science, Iran University of Medical Science, Tehran, Iran; ${ }^{6}$ Faculty of Management. University of Tehran, Tehran, Iran;

\section{Keywords}

Electronic medical record (EMR), physician, technology acceptance model (TAM), diffusion of innovation theory (DOI), structural equation modeling (SEM)

\section{Summary}

Background: In order to fulfill comprehensive interoperability and recognize the electronic medical records (EMRs') benefits, physicians' attitudes toward using and applying EMR must be recognized. Objectives: The purpose of this study was to present an integrated model of applying EMRs by physicians.

Methods: This was a cross sectional study in which a sample of 330 physicians working in hospitals affiliated to the Tehran University of medical sciences (TUMS) was selected. Physicians' attitudes toward using and accepting EMR in health care have been analyzed by an integrated model of two classical theories i.e. technology acceptance model (TAM) and diffusion of innovation (DOI). The model was tested using an empirical survey. The final model was tested by structural equation modeling (SEM) and represented by Analysis of Moment Structures (AMOS).

Results: The results suggest that the hybrid model explains about 43 percent of the variance of using and accepting of EMRs ( $R 2=0.43$ ). The findings also evidenced that Perceived Usefulness (PU), Perceived Ease of Use (PEOU), Relative Advantage, Compatibility, Complicatedness and Trainability have direct and significant effect on physicians' attitudes toward using and accepting EMRs. But concerning observeability, significant path coefficient was not reported.

Conclusions: The integrated model supplies purposeful intuition for elucidates and anticipates of physicians' behaviors in EMRs adoption. The study identified six relevant factors that affect using and applying EMRs that should be subsequently the major concern of health organizations and health policy makers.

\section{Correspondence to:}

Maryam Ahmadi

Department of health information management, school of Management and medical information science

Iran university of Medical Science

Tehran, Iran

Email: M-ahmadi@tums.ac.ir

Phone: 009888772086

Fax: 009888772086

\author{
Appl Clin Inform 2016; 7: 341-354 \\ http://dx.doi.org/10.4338/ACI-2015-11-RA-0165 \\ received: December 30, 2015 \\ accepted: February 26, 2016 \\ published: May 11, 2016 \\ Citation: Abdekhoda M, Ahmadi M, Dehnad A, Noruzi \\ A, Gohari M. Applying electronic medical records in \\ health care: Physicians' perspective. Appl Clin Inform \\ 2016; 7: 341-354 \\ http://dx.doi.org/10.4338/ACI-2015-11-RA-0165
}




\section{Introduction}

Electronic Medical Records (EMRs) are defined as computerized medical information systems and in advance seems to change the existing, often paper based, medical practice. Collecting, sharing and having access to patients' clinical information are attainable by EMRs as they are acknowledged as the tools to create legible and structured records of patients' information [1]. Many healthcare organizations are endeavoring to design and implement these systems for collecting, storing and displaying patients' information at the point of care because EMR systems provide facilities such as reducing medical errors, increasing effectiveness of healthcare services, and reducing healthcare costs [2]. Being recognized as potential means of improving quality, permanence, safety and effectiveness of healthcare services, EMRs are planned and implemented across the world [1].

In spite of the high potential and widespread focus on EMRs, especially in developing countries, their overall use and adoption rate are comparatively low, due to challenges such as establishing a system that absorbs significant financial resources, requiring the capacity to deal with computers, and making changes in physicians' traditional working styles [1, 3, 4].Moreover, healthcare institutions, policymakers, and customers believe that changing and transforming healthcare services are critical and can be attained by healthcare information technologies such as EMRs [5]. Otherwise, health information technology adoption is tool to enhance clinical efficiency, improve quality of services and reduce healthcare costs [6].

Recently, efforts to understand and predict human factors and issues related to technology implementation have been increasingly acknowledged. Concerning EMRs design and implementation, these consist of inadequate usability of EMR user interface, patients' attitude toward EMRs, and resistance among physicians for EMRs acceptance [2]. To find opportunities toward developing improved approaches in EMRs implementation process, comprehensive recognition and understanding of user-group experience, organizational changes and problems created by EMRs technology; are unavoidable [2].

Physicians have a high impact on the overall adoption rate of EMRs. They are the main frontline end-users group of EMRs. Whether or not physicians adopt and use EMRs will have a great impact on other users such as nurses, information managers and administrative staff. Therefore, the slow rate of EMRs adoption implies that physician resistance must be strong [1].

Physicians' perception toward EMRs adoption is crucial to realize worldwide interoperability, achieve the benefits of it, and understand the factors affecting physicians' attitudes toward using and adopting EMRs [1]. However, the researchers have found no studies evaluating factors affecting physicians' attitudes toward the use and adoption of EMRs, especially in Iran. This study integrated the TAM and DOI to take advantage of both theoretical models. This proposed model will better reveal how different factors influence physicians' attitudes toward using and accepting EMRs. The purpose of the present study was to confirm a hypothesized correlational model for predicting physicians' attitudes toward using and accepting EMRs ( $>$ Figure 1).

\subsection{Theory and Hypotheses}

A wide variety of theoretical perspectives have emerged to understand users' mental processes when IT adoption and its implementation are considered by organizations. Nevertheless, most of the theories in this area have failed to provide acceptable measures that could evaluate and explain endusers' behavior in a system acceptance or rejection [7].

The Technology Acceptance Model (TAM) [8], the Unified Theory of Acceptance and Use of Technology (UTAUT) [9], Theory of Planned Behavior (TPB) [10] and Innovation Diffusion Theory (IDT) [11]; appear to be the main dominant IT theories providing an acceptable model for understanding the success and failure of an information system. However, we will not be able to understand the reasons responsible for the success and failure of IT systems without a comprehensive understanding and using of such theories because these theories present appropriate tools for assessing the success and failure of IT systems [12]. For instance, in a study UTAUT have been applied to predict and achieve the best understanding of end-users' behavior acceptance of picture archiving and communication system (PACS) in a radiology setting [13]. 
Technology Acceptance Model (TAM) developed by Davis in 1998[8], elucidates the adoption and acceptance of information technology in fulfilling tasks and presenting two basic ideas affecting the acceptance of information systems: perceived usefulness (PU) and perceived ease of use (PEOU). PU is defined as "the degree to which an individual believes that using a particular system will enhance his or her job performance." PU is related to job effectiveness, productivity, time saving, and the relatively significant role of systems in a user's job. On the other hand, PEOU is defined as "the degree to which an individual believes that using a particular system is free of effort" [14], i.e., physical and mental efforts as well as ease of learning. External variables containing end-user characteristics such as gender, level of education and organizational features such as job training have been found to influence PU and PEOU as well as users' intention to use information technology [14].

The diffusion of innovation is defined as technology separation through a population of potential adopters. Explaining and anticipating rates and patterns of technology and innovation adoption in actual time and space are the main purposes of DOI studies. The five attributes of DOI influencing the level of using and accepting innovation, are defined by Rogers as: relative advantage (RA), compatibility, complicatedness, trialability and observability. Relative advantage is "the degree to which an innovation such as EMR is perceived as superior to the innovation it supersedes" [15]. Compatibility refers to "the degree to which an innovation is perceived as consistent with the individual's existing values, beliefs, past experiences, and needs". Complicatedness is "the degree to which an innovation is perceived as relatively difficult to understand and use". Specifically, it should speculate the controversy of ease of use as acknowledged in many of the behavioral intent models such as TAM [15]. Trialability is "the degree to which an innovation will be available for trial usage before adoption" [15]. Finally, Rogers defined observability as "the degree to which the results of an innovation are visible to others. Innovation whose outcomes are easily observed tends to be adopted faster than those with more subtle outcomes" [16].The five features of Rogers' model are classified into three categories; subjective evaluation, objective conditions and interaction factors ( $\$$ Fig. 1).

In the context of healthcare, DOI has been applied to explain how clinicians accept and prescribe new medications along with healthcare technologies such as electronic medical records [17]. Better understanding of the concept and attributes of each phase of DOI process can helps social group to persuade and embrace changes more easily, also new procedures take place more smoothly in the field of new technology adoptions [16].

When put together, two classical theories, TAM and DOI, create an integrated framework for a better recognition and prediction of user acceptance and adoption of technological innovations. Organizational context, technologies, and characteristics of individuals are commonalities of the two theories [18]. A set of features for innovation have subsequently been confirmed on the basis of the strong similarities between TAM and DOI. Furthermore, a precise analysis of TAM indicates that this model has considerable capacity to integrate in to and extended model such as DOI, for better understanding the human behavior in accepting and adopting new technology such as EMR. The prediction of physicians' attitude toward using and accepting EMR may be illustrated by applying TAM as a predictive model and by consolidating external variables pertaining to end-user, the innovation and the organizational context [19].

Attitudes toward using information systems is controlled significantly by the end-users' perception of usefulness and ease of use [20-21]. The literature shows that PU is the precedent of healthcare practitioners' intention for accepting and using information systems such as EMRs; however, contradictory findings for the correlation between PEOU and attitudes toward using information systems were reported [21-22]. For instance, Lee (2003) reported that among 101 studies, only 58 of them showed a significant correlation between PEOU and actual use of information systems, indicating that PEOU is not a stable measure in predicting dependent variables [23].

The literate showed that PEOU could indirectly influence the IT adoption through PU and should be considered as a determining factor in IT acceptance [24]. Thus, the following hypotheses, $\mathrm{H} 1$ and $\mathrm{H} 2$, were put forth:

H1: PU is positively associated with physicians' attitudes toward using and accepting EMRs.

H2: PEOU is positively associated with physicians' attitudes toward using and accepting EMRs. 
Relative advantage, user subjective estimation about a specific information system, is defined by users' personalities and technology characteristics will influence the PU positively as stated in the following hypothesis:

H3: Perceptions of relative advantage of the EMR will have a positive effect on PU.

Compatibility and complicatedness as categorized under interacting factors of DOI seem to have a great impact on PU and PEOU. Previous studies report that there are great and significant correlation between compatibility with PU and PEOU. Furthermore, compatibility has great and significant impact on PU and PEOU $[16,17,25,26]$. Also, the literature shows complicatedness has an important role in accepting and adopting new technologies such as EMRs; for example, Ardis (1998), Vollink (2002), Atkinson (2007) and lee (2004), acknowledged there are negative and significant correlation between complicatedness with PU and PEOU [16, 27-29]. Conversely, Wu (2008) fond that complicatedness had no negative effect on using E-CRM systems [30]. Therefore, hypotheses H4-H7 were followed by this study:

H4: the perception of compatibility of EMRs will have a positive effect on PU.

H5: the perception of compatibility of the EMRs will have a positive effect on PEOU.

H6: the perception of complicatedness of EMRs will have a negative effect on PU.

H7: the perception of complicatedness of EMRs will have a negative effect on PEOU.

Observability and trialability, categorized as objective conditions, are closely related to PEOU and show users' perception of information systems adoption [25]. There are several studies approving the positive and significant correlation between observability and PEOU. Observability has also been found to have a significant effect on PEOU [17, 27, 28, 30-31]. Cho and et al (2014) reported that cognitive factors had a direct effect on medical staff' adoption of health applications [32]. Moreover, Kendal (2001), Greer (2003), Faiers (2007), Wu (2008) and Conrad (2009) noted that trialability had a positive and significant correlation with PEOU. Trialability has also been found to have a great and significant impact on PEOU [30, 33-36]; hence, hypotheses, H8 and H9, were presented as follows:

H8: the perception of EMR observability will have a positive effect on PEOU.

H9: the perception of EMR trialability will have a positive effect on PEOU.

Figure 1 summarizes hypotheses and presents the proposed conceptual path model of TAM and DOI integrated model.

\section{Methods}

This study was conducted from August to October 2013 at hospitals affiliated to Tehran University of medical sciences (TUMS). The research methodology consists of these steps: determining population and research setting, developing and modifying the survey, pre-testing the survey instrument, distributing the questionnaire, collecting the data and finally analyzing the results.

Currently, in Iran, the government encourages and rewards IT adoption such as electronic medical records and online prescriptions, especially in the healthcare industry and medical science universities. The population of this study included all physicians working in hospitals affiliated to TUMS. A sample of 330 of them was selected by stratified random sampling. TUMS University was selected as the setting of this study because TUMS is the first rank medical university in Iran, and a considerable intention for adoption of recent technologies has been pursued in this university.

A researcher-made questionnaire for data collection was developed on the basis of Wilkins' (2008), Nair's (2011), Morton' (2008) and Conrad's (2009) questionnaires. Wilkins evaluated heath information mangers' PU and PEOU toward electronic heath care record system [37]. Nair used technology acceptance model to elucidate the heath care behavior in adopting electronic health records [38]. Morton applied integrated model of TAM and DOI to recognize factors affecting physicians' attitudes toward using Electronic Health Records (EHRs) [18]. Also, Conrad conducted a study to examine some key determinants of individual willingness to use a new technology by utilizing a framework grounded in TAM and DOI [33]. 
Five faculty members of the health information management department in TUMS confirmed the content and face validity of the survey instrument. Test-retest was used to measure the reliability of questionnaires (91.2). The survey included structured questions on PU, PEOU, relative advantage, compatibility, complicatedness, observability and trialability of EMRs. There were also a number of demographic questions. "Totally agree," "agree," neutral" "disagree," and "totally disagree," formed the questionnaire which was based on a 5-point Likert scale. In this study, seven aspects of Rogers's theory, i.e., relative advantage, compatibility, complicatedness, observability and trialability, perceived usefulness and perceived ease of use were considered as independent variables, while physicians' attitudes toward using and accepting EMRs were dependent variables.

The survey was performed by using TUMS webmail services. An introductory e-mail describing the purpose of the survey was sent to the participants of the study. Also the ethical approval was approved by TUMS ethical committee. From 330 questionnaires, 278 of them were completed and returned (response rate $=84.24$ ), but at the end, 237 questionnaires were appropriate for analysis. Because of partially filled out or presenting misconducts information, 41 questionnaires were not appropriate for analysis.

To determine the correlation between variables and to simplify the model prior to testing, a correlation matrix was constructed. Moreover, to test the proposed research model, a graphical path model was expanded. The collected data were analyzed by SPSS $_{16}$. The correlation between variables was measured by Pearson's correlation and regression tests. Structural Equation Modeling (SEM) was used to analyze the predicted paths. SEM is the preferred approach for analyzing interactions between multiple independent and depended variables, such as those used in this study. The proposed conceptual path model ( $>$ Figure 1) was developed using AMOS ${ }_{16.0}$ SEM software. Finally, the modified model was presented. $>$ Table 1 show the questions used in the survey measuring the various constructs in the integrated model.

\section{Results}

Table 2 shows demographic information describing the study sample. As this table shows, majority of the respondents (54 percent) were female. The mean age of the participants was 31 , and 40 percent of the participants were in the age range of 31-35. More than half of the participants (54.4 percent) were general practitioners (GPs). The mean year of 6.07 for the physicians' work experience was reported in this table and the data showed that 43 percent of participants had 1-5 years of work experience.

Table 3 shows the correlation between variables of proposed conceptual path model. As it is seen, there are significant correlations between exogenous (DOI characteristics) and endogenous model variables (TAM variables). Also the results of this table show there are positive and significant correlations between endogenous variables of model.

Also, Table 3 indicates a positive and significant correlation between EMR usage and PU and PEOU. Also, a great, positive and significant correlation between PU and PEOU was found. There was a significant correlation between RA, PU and PEOU. It was also found that, compatibility was correlated significantly and positively with usage, PU and PEOU. This table shows there are negative and significant correlation between complicatedness and EMR usage, PU and PEOU. Furthermore, the positive and significant correlation between objectives conditions, i.e. observeability and trialability, with PU and PEOU were reported.

The results of the validated proposed conceptual path model are presented in $>$ Figure 2 . According to this figure, $\mathrm{PU}$ has a direct and significant effect on using and accepting EMRs $(\beta=0.26, \mathrm{P}=$ 0.04). Also PEOU has a strong, direct and significant effect on EMRs usage and acceptance $(\beta=$ $0.51, \mathrm{P}=0.001)$. Furthermore, this figure shows that the model explains about 43 percent of the variance of using and accepting EMRs $\left(\mathrm{R}^{2}=0.43\right)$.

Figure 2 shows the positive and significant path coefficient of RA to $\mathrm{PU}(\beta=0.44, \mathrm{P}=0.000)$. In addition this figure shows compatibility has the greatest direct effect on PU with a highly significant path coefficient of 0.53. Also, compatibility has a direct and significant effect on PEOU with an acceptable path coefficient rate $(\beta=0.35, \mathrm{P}=0.000)$. Figure 2 illustrates complicatedness has a 
negative and significant effect on $\mathrm{PU}(-\beta=0.32, \mathrm{P}=0.04)$. Also, a negative and significant path coefficient between complicatedness and PEOU was reported.

- Figure 2 shows observability does not have a significant effect on POEU whereas trialability has a direct and significant effect on PEOU $(\beta=0.11, \mathrm{P}=0.02)$. Altogether, relative advantage, compatibility and complicatedness were able to explain 53 percent of the variance observed in PU. Furthermore, this figure shows that compatibility, complicatedness and trialability explain about 62 percent of the variance of PEOU.

Model fit was measured by the evaluation of several model fit indices. The relative $\mathrm{X}^{2}$ or ratio $\mathrm{X}^{2}$ was used to test whether the selected distribution was a good fit to the data. A relative $\mathrm{X}^{2}$ value of 1.06 was obtained which was favorable. Tucker- Lewis index (TLI), comparative fit indices (CFI), Normal fit index (NFI), Relative Fit Index (RFI) and Root Mean Squared Error of Approximation (RMSEA), were measured and appeared to be acceptable. Table 4 summarizes recommended goodness-of-fit measure.

\section{Discussion}

This study combined two classical theories, TAM and DOI, to validate the proposed conceptual path model and to understand factors that affect EMR acceptance and adoption by physicians.

Physicians' resistance toward adopting and accepting EMRs appeared to be the main barrier to fulfill comprehensive interoperability and achieve the benefits that EMRs can provide. Understanding the factors affecting physicians' attitudes toward the use and adoption of EMRs is necessary, as it is crucial that physicians use and adopt EMRs, realize its comprehensive interoperability and make use of its benefits.

Regarding the association between PU and EMR acceptance, the standard coefficient of PU and EMR acceptance was 0.26 with a p-value of 0.05 , supporting $\mathrm{H} 1$. This finding is in line with the findings of Morton (2008), Kowitlawalkul (2008), Zhang (2008) and Holdan (2010) reporting a positive and significant path coefficient rates between PU and EMR acceptance [18, 25, 39-40]. On the other hand, it was reported that PEOU positively affected EMR acceptance with the standard coefficient of 0.51 (p-value $=0.01$ ) which supports $\mathrm{H} 2$, suggesting that PEOU is positively associated with physicians' attitudes toward using and accepting EMRs. This finding supports the findings of the studies conducted by Kowitlawalkul (2008) and Zhang (2008) [25, 39] whereas it is in contrast with the finding of Morton (2008) reporting that there was no significant coefficient between PEOU and EMR acceptance [18] and Subramanian finding no significant relationship between PEOU and attitude toward using information technology (1994) [41]. Igbaria (1995) discussed that "the hard reality of organizations might put priority on the usefulness of computer systems rather than the pleasure brought by them" [42]; however, it could be implied from the findings of the present study and several similar studies such as Kowitlawalkul (2008), Zhang (2008), Pai (2010) and Ortega Egea (2011) that PEOU should not be underestimated as it strongly affects the use and acceptance of information system $[25,39,43,44]$. Also, Gagnon et al (2012) reported that "perception of the benefits of the innovation (system usefulness) was the most common facilitating factor, followed by ease of use" [45].

Concerning the association between RA and PU, the standard coefficient of RA and PU were found to be 0.44 with a p-value of 0.001 ; thus, $\mathrm{H} 3$ was supported, indicating that the perceptions of relative advantage of EMR would have a positive effect on PU. Likewise, Zhang (2008), Wu (2008), Conrad (2009) and Ping Yu (2009) found that RA had a strong, direct and significant effect on PU $[25,30,33,46]$.On the basis of the findings of this study and several similar studies, it could be concluded that relative advantage is an important factor that positively and significantly affect EMR use and acceptance.

In terms of the relationships between compatibility with PU and PEOU, the finding show in $>$ Figure 2 suggest that compatibility had a direct and significant effect on $\mathrm{PU}(\beta=0.5, \mathrm{P}=0.001)$. Hence, $\mathrm{H} 4$ was supported suggesting that the perception of compatibility of the EMR would have a positive effect on PU. Moreover, a direct and significant path coefficient between compatibility and PEOU is reported in Figure $2(\beta=0.35, \mathrm{P}=0.001)$ supporting $\mathrm{H} 5$, and suggesting that the perception of compatibility of EMRs will have a positive effect on PEOU. This finding is in line with the findings of 
Oh (2003), chew (2004), Zhang (2008) and Tung (2008) who reported that compatibility had a direct and significant effect on both PU and PEOU. Therefore, compatibility should be recognized as an important factor when using and adopting information systems such as EMRs [17, 25, 26, 47].

As for association among complicatedness with PU and PEOU, the results of this study showed that complicatedness had a negative and significant effect on PU $(-\beta=0.32, \mathrm{P}=0.005)$; thus, H6 was supported, suggesting that the perceptions of complicatedness of EMR will have a negative effect on PU. On the basis of the findings, it could be inferred that there is an indirect and significant path coefficient rate between complicatedness and PEOU $(-\beta=0.41, \mathrm{P}=0.0001)$ supporting $\mathrm{H} 7$ and showing that the perceptions of complicatedness of EMR will have a negative effect on PEOU. The results of this study support the findings of studies conducted by Ardis (1998), Vollinic (2002), oh (2003) Lee (2004) and Atkinson (2007) who found that complicatedness had a strong and negative effect on both PU and PEOU, [16, 27-29, 47]. Unexpectedly, Wu (2008) found that complicatedness had no indirect effect on accepting and adopting E-CRM [30]. However, when the application of a specific information system is accompanied with complicatedness, users' tendency to use the system decreases considerably.

Regarding the association between observability and PEOU, the results from $>$ Figure 2 show that the standard coefficient between observability and PEOU is not significant. Therefore, H8 was not supported. Zhang (2008) found that the standard coefficient between observability and PEOU was significant (0.13 with the p-value of 0.05) [25]. Whereas, Sanayie (2012) noted that observability had no significant and direct effect on PEOU [48].

Finally, concerning the association between trialability and PEOU, the results showed that trialability had a direct and significant effect on PEOU $(\beta=0.11, \mathrm{P}=0.005)$; hence, H9 was supported, suggesting that the perception of trialability of EMR will have a positive effect on PEOU. Kendal (2001), Chew (2004), Faiers (2007), Conrad (2009) and Sanayie (2012) also found that trialability had a direct and significant effect on PEOU suggesting that, trialability is an important factor that should be taken into consideration to achieve successful implementation of EMRs.

- Figure 2 also shows that the model explains about 43 percent of the variance for EMRs used and accepted by physicians. Furthermore, the results of this study confirmed that 53 percent of the variance of $\mathrm{PU}$ and 62 percent of that of PEOU are explained by five DOI constructs as antecedents for two key factors of TAM.

All-told the contribution of this study to research on the adoption and acceptance of EMR is fivefold. First, this study combined two classical theories, TAM and DOI, and proposed a new and constructive hybrid technology model. Second, the results of this study showed that relative advantage had a positive and significant effect on PU. Moreover, compatibility had a significant direct effect on both PU and PEOU. There were also a significant and negative path coefficient rates reported from complicatedness for both PU and PEOU, suggesting that complicatedness had a negative effect on both PU and PEOU. Finally, this study revealed that objective conditions, trialability and observability, had an inconsistent impact on PEOU. While trialability had a significant and positive effect on PEOU; significant path coefficient between observability and PEOU was not observed.

Self-reported use of EMRs by participants, instead of measuring the actual use of it, limiting the setting of this study to teaching hospitals, and self-selection biases of the items in the questionnaire, are some of the limitations which need to be addressed in future studies. There are also several factors such as security and confidentiality which were not examined in this study but may influence constructs in TAM and DOI model.

\section{Conclusion}

This study integrated two classical theories, TAM and DOI, to confirm and expand the EMR acceptance model, and thereby makes a significant contribution both academia and practice. This is the first study carried out in Iran, to examine a new hybrid technology acceptance model with the aim of proposing a conceptual model for successful adoption of EMR. Results from SEM analysis demonstrated that the model provided meaningful intuitions for perception, elucidation and anticipation of EMRs adoption by physicians. The present study clearly identified six relevant factors influencing physicians' attitudes toward accepting and adopting EMRs, i.e., perceived usefulness, per- 
ceived ease of use, relative advantage, compatibility, complicatedness and trialability of the EMRs. Future studies should develop the proposed model and focus on other factors such as physicians 'characteristics, institutional issues, and security factors. Moreover, research to identify factors that affect attitudes toward acceptance and adoption of EMRs among other staff, including nurses, managers and pharmacists, is recommended.

Conflict of interest

No conflict of interest declared.

\section{Human Subjects Protections}

No human subjects were involved in the study.

Acknowledgment

This study was funded by a grant from TUMS. 


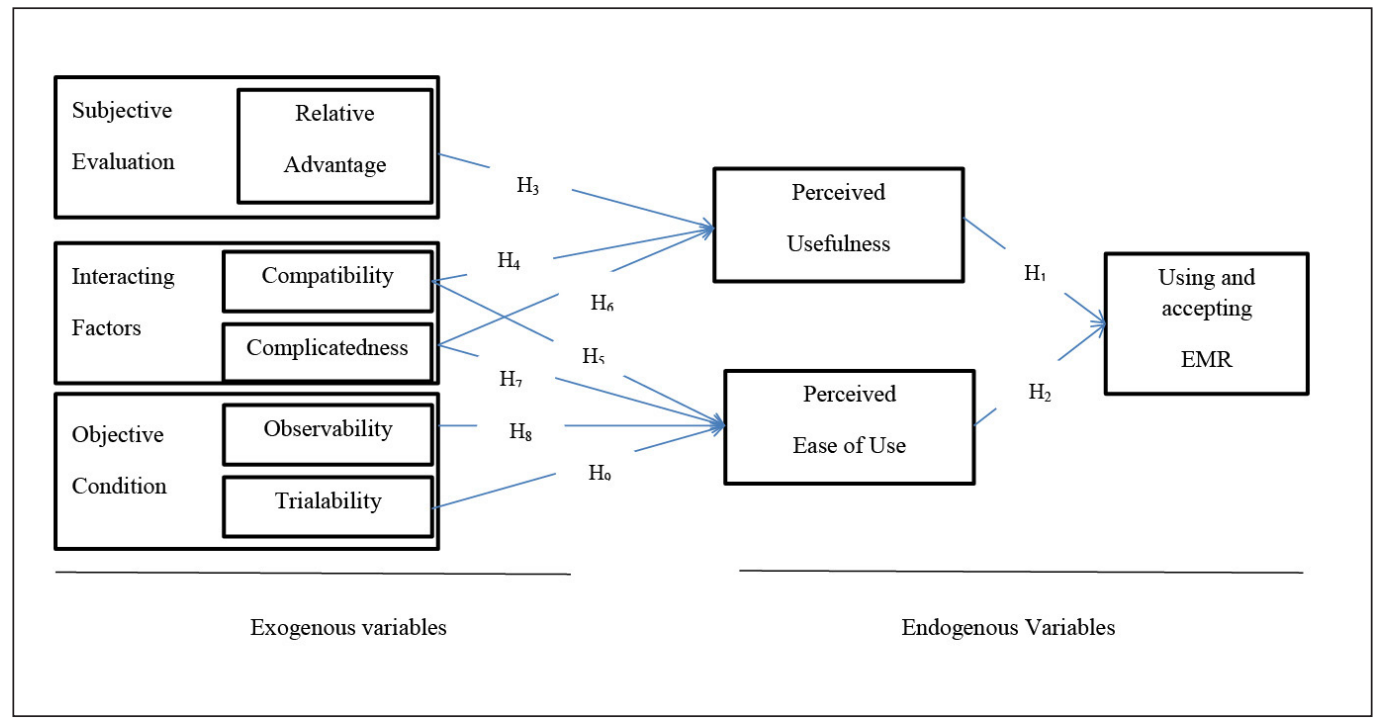

Fig. 1 Hypotheses and proposed conceptual path model of TAM and DOI integrated model

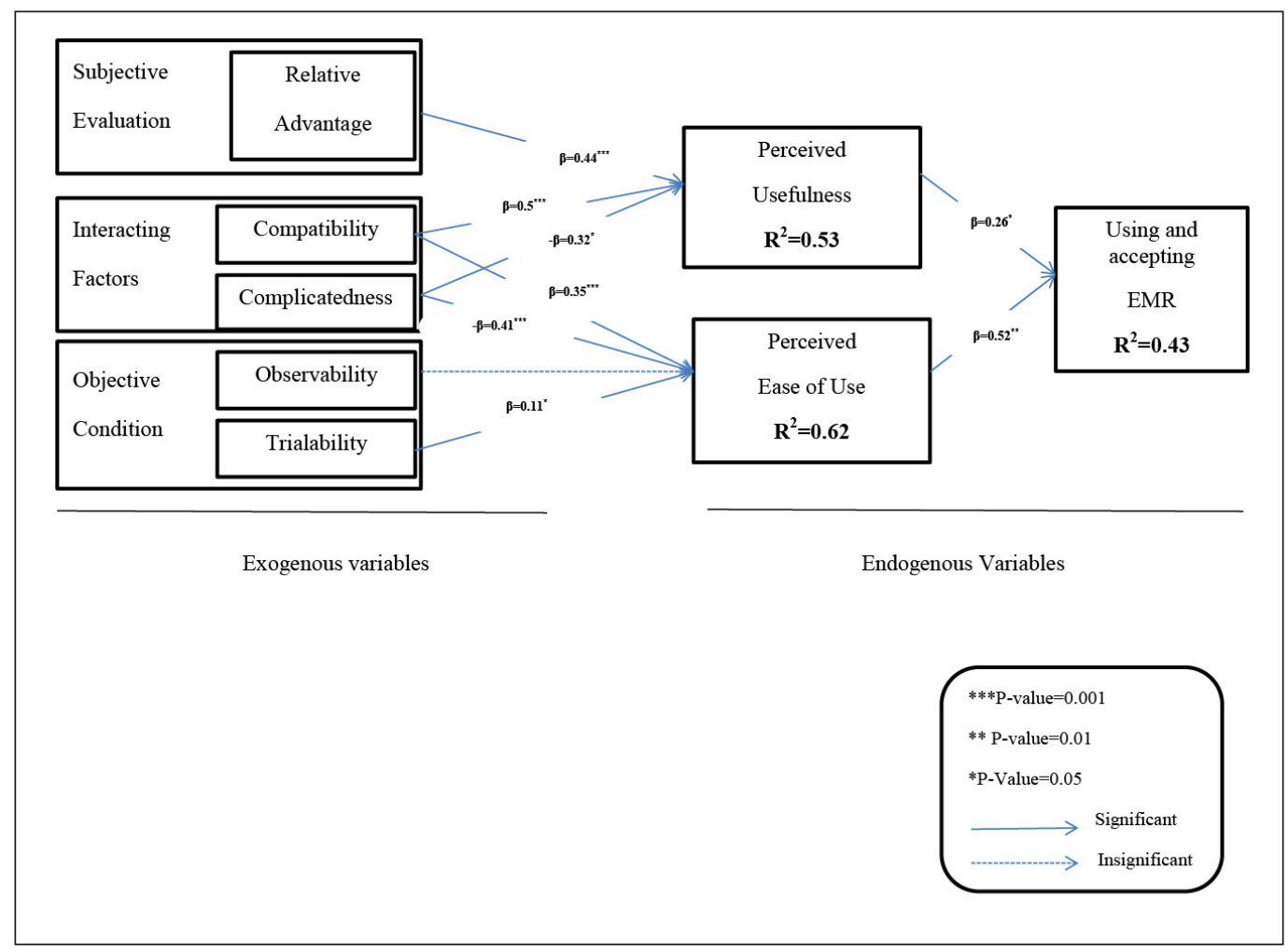

Fig. 2 Validating proposed conceptual path model' results 
Table 1 Items used to measure the various constructs in the integrated model

\begin{tabular}{|c|c|c|}
\hline Construct & $\begin{array}{l}\text { Item } \\
\text { Number }\end{array}$ & Items \\
\hline \multirow{4}{*}{$\begin{array}{l}\text { Perceived useful- } \\
\text { ness }\end{array}$} & 1 & Appling EMRs in my job would enable me to accomplish tasks more quickly. \\
\hline & 2 & Appling EMRs improve my job performance. \\
\hline & 3 & Appling EMRs would make it easier to do my job. \\
\hline & 4 & Appling EMRs are useful in my job. \\
\hline \multirow{4}{*}{$\begin{array}{l}\text { Perceived Ease of } \\
\text { Use }\end{array}$} & 5 & I believe that interaction with EMRs would be clear and understandable. \\
\hline & 6 & I believe navigation of EMRs would be easy. \\
\hline & 7 & Learning to operate EMRs would be easy for me. \\
\hline & 8 & It would be easy for me to become skillful at using EMRs. \\
\hline \multirow{3}{*}{$\begin{array}{l}\text { Using and } \\
\text { Accepting EMRs }\end{array}$} & 9 & I use EMRs in my work routinely. \\
\hline & 10 & In future, I would like to adopt EMR in my work. \\
\hline & 11 & $\begin{array}{l}\text { In my job, considerable part of routinely work was carried out by adopting } \\
\text { EMR. }\end{array}$ \\
\hline \multirow{4}{*}{$\begin{array}{l}\text { Relative } \\
\text { advantage }\end{array}$} & 12 & Adopting EMR, improve the quality of my work. \\
\hline & 13 & Using EMRs improves my job performance. \\
\hline & 14 & Adopting EMR causes enhance effectiveness in my job. \\
\hline & 15 & By adopting EMR, my work productivity will increase. \\
\hline \multirow[t]{3}{*}{ Compatibility } & 16 & Using EMRs is compatible with all aspects of my work. \\
\hline & 17 & Using EMRs is completely compatible with my current situation. \\
\hline & 18 & Using EMRs fits into my work style. \\
\hline \multirow[t]{4}{*}{ Complicatedness } & 19 & I believe that EMRs is complicated to use. \\
\hline & 20 & It is difficult for me to remember how to perform tasks using EMRs. \\
\hline & 21 & Using EMRs is often frustrating. \\
\hline & 22 & Adopting EMRs need a lot of mental effort. \\
\hline \multirow[t]{4}{*}{ Observeability } & 23 & I have seen what others do using EMRs. \\
\hline & 24 & EMRs are very visible in my organization. \\
\hline & 25 & I've plenty of opportunity to see the EMRs being used. \\
\hline & 26 & I have seen EMRs in use outside my organization. \\
\hline \multirow[t]{4}{*}{ Trialability } & 27 & I've a great deal of opportunity to try various EMRs applications. \\
\hline & 28 & I know where I can go to satisfactorily try out various uses of EMRs. \\
\hline & 29 & $\begin{array}{l}\text { I was permitted to use EMRs on a trial basis long enough to see what it could } \\
\text { do. }\end{array}$ \\
\hline & 30 & $\begin{array}{l}\text { There are enough people in my organization to help me try the various uses of } \\
\text { the EMRs. }\end{array}$ \\
\hline
\end{tabular}


Table 2 Demographic information of the sample

\begin{tabular}{|c|c|c|c|c|c|}
\hline Demographics & Category & Freq. & Per. & Mean & S.D \\
\hline \multirow[t]{4}{*}{ Gender } & Male & 66 & 27.8 & & \\
\hline & Female & 130 & 54.9 & & \\
\hline & Missing & 41 & 17.29 & & \\
\hline & Total & 237 & 100 & & \\
\hline \multirow[t]{7}{*}{ Age } & $25-30$ & 62 & 26.3 & \multirow{7}{*}{31.8} & \multirow{7}{*}{2.09} \\
\hline & $31-35$ & 85 & 35.9 & & \\
\hline & $36-40$ & 46 & 19.42 & & \\
\hline & $40-45$ & 9 & 3.8 & & \\
\hline & $45 \leq$ & 1 & 0.4 & & \\
\hline & Missing & 34 & 14.3 & & \\
\hline & Total & 237 & 100 & & \\
\hline \multirow[t]{5}{*}{ Degree } & General practitioner & 102 & 43 & & \\
\hline & Specialists & 129 & 54.4 & & \\
\hline & Fellowship & 3 & 1.3 & & \\
\hline & Missing & 3 & 1.26 & & \\
\hline & Total & 237 & 100 & & \\
\hline \multirow[t]{5}{*}{ Work experience } & $1-5$ & 102 & 43 & \multirow{5}{*}{6.07} & \multirow{5}{*}{3.1} \\
\hline & $5-10$ & 32 & 13.5 & & \\
\hline & $10 \leq$ & 16 & 6.8 & & \\
\hline & Missing & 87 & 36.7 & & \\
\hline & Total & 237 & 100 & & \\
\hline
\end{tabular}

Table 3 Correlation between variables of proposed conceptual path model ${ }^{1,2}$

\begin{tabular}{|c|c|c|c|c|c|c|c|c|}
\hline Constructs & Usage & PEOU & PU & RA & Compat. & Complic. & Observ. & Trial. \\
\hline Usage & 1 & & & & & & & \\
\hline PEOU & $0.614^{* *}$ & 1 & & & & & & \\
\hline PU & $0.562^{* *}$ & $0.624^{* *}$ & 1 & & & & & \\
\hline RA & $0.205^{* *}$ & 0.518 ** & $0.646^{* *}$ & 1 & & & & \\
\hline Compat. & 0.192 ** & $0.767^{* *}$ & $0.673^{* *}$ & $0.571^{* *}$ & 1 & & & \\
\hline Complic. & $-0.389 * *$ & $-0.744^{* *}$ & $-0.627^{* *}$ & $-0.612^{* *}$ & $-0.730^{* *}$ & 1 & & \\
\hline Observ. & $0.268^{* *}$ & $0.555^{* *}$ & 0.451 ** & $0.678^{* *}$ & $0.538^{* *}$ & $-0.683^{* *}$ & 1 & \\
\hline Trial. & $0.253^{* *}$ & 0.586 ** & $0.488^{* *}$ & 0.696 ** & $0.528^{* *}$ & -0.695 ** & $0.825^{* *}$ & 1 \\
\hline
\end{tabular}

1) ** P-value is significant at 0.01 levels.

2) PEOU: perceived ease of use; PU: perceived usefulness; RA: Relative Advantage; Compat: Compatibility; Complic: Complicatedness; Observ: Observability; Trial: Trialability 
Table 4 Recommended goodness-of-fit measure

\begin{tabular}{|l|l|l|c|}
\hline $\begin{array}{l}\text { Fit index } \\
\text { category }\end{array}$ & Suggested index & Suggested value & Obtained value \\
\hline Absolute fit & Relative X2 & Relative X2 <3.0 & 1.06 \\
\hline Incremental fit & Tucker-Lewis Index(TLI) & .90 or above acceptable fit & .98 \\
\hline Incremental fit & Comparative fit index(CFI) & .90 or above & .92 \\
\hline Incremental fit & Normal fit index (NFI) & .90 or above & .99 \\
\hline Incremental fit & Relative Fit Index(RFI) & .90 or above & .96 \\
\hline Parsimonious fit & $\begin{array}{l}\text { Root Mean Squared Error of Approxi- } \\
\text { mation (RMSEA) }\end{array}$ & $\leq 0.1$ & .05 \\
\hline
\end{tabular}




\section{References}

1. Boonstra A, Broekhuis M. Barriers to the acceptance of electronic medical records by physicians from systematic review to taxonomy and interventions. BMC health services research 2010; 10(1): 231.

2. Carayon $P$ et al. Implementation of an electronic health records system in a small clinic: the viewpoint of clinic staff. Behaviour \& Information Technology 2009; 28(1): 5-20.

3. Abdekhoda $\mathrm{M}$ et al. Factors affecting information technology acceptance by health information management (HIM) staff of Tehran University Of Medical Sciences' Hospitals based on the technology acceptance model (TAM) in 2011. Payavard Salamat 2013; 7(4): 287-298.

4. Abdekhoda $\mathrm{M}$ et al. Information technology acceptance in health information management. Methods of information in medicine 2014; 53(1): 14-20.

5. Chaudhry B. et al. Systematic review: impact of health information technology on quality, efficiency, and costs of medical care. Annals of internal medicine 2006; 144(10):742.

6. Putzer GJ, Park Y. Are physicians likely to adopt emerging mobile technologies? Attitudes and innovation factors affecting smartphone use in the Southeastern United States. Perspectives in health information management/AHIMA, American Health Information Management Association 2012; 9(Spring).

7. Davis FD, Bagozzi RP, Warshaw PR. User acceptance of computer technology: a comparison of two theoretical models. Management science 1989; 35(8): 982-1003.

8. Davis FD. Perceived usefulness, perceived ease of use, and user acceptance of information technology. MIS quarterly 1989; Sep 1: 319-40

9. Venkatesh V, Davis FD. A theoretica l extension of the technology acceptance model: four longitudinal field studies. Manage Sci 2000; 46(2): 186-204.

10. Fishbein M, Ajzen I. Belief, attitude, intention, and behavior: An introduction to theory and research. Addison-Wesley Pub Co 1975.

11. Rogers EM. Diffusion of innovations: Free Pr 1995.

12. Koivunen M. Acceptance and use of information technology among nurses in psychiatric hospitals. 2009. Available at http://doria32-kk.lib.helsinki.fi/handle/10024/43661

13. Duyck $P$ et al. User acceptance of a picture archiving and communication system - applying the unified theory of acceptance and use of technology in a radiological setting. Methods of information in Medicine 2008; 47(2): 149-156.

14. Gupta A. Exploring the acceptance and barriers to usage of information and communication technology by Irish occupational therapists. 2010.

15. Rogers EM. Diffusion of innovations. 5th Ed. New York: Free Press; 2003.

16. Lee TT. Nurses' adoption of technology: application of Rogers' innovation-diffusion model. Applied Nursing Research 2004; 17(4): 231-238.

17. Chew F, Grant W, Tote R. Doctors on-line: using diffusion of innovations theory to understand internet use. Family Medicine-Kansas City 2004; 36: 645-650.

18. Morton ME. Use and acceptance of an electronic health record: factors affecting physician attitudes [Retrieved From Proquest Dissertations And Theses Database. (Umi No. 3327272)]: Drexel University; 2008.

19.Legrisa P, Inghamb J, Collerettec P. Why do people use information technology? A critical review of the technology acceptance model. Information \& Management 2003; 40(3): 191-204.

20.Gefen D, Karahanna E, Straub DW. Trust and TAM in online shopping: An integrated model. MIS quarterly 2003: 51-90.

21. Schepers J, Wetzels M. A meta-analysis of the technology acceptance model: Investigating subjective norm and moderation effects. Information \& Management 2007; 44(1): 90-103.

22. Ma Q, Liu L. The technology acceptance model: a meta-analysis of empirical findings. Journal of Organizational and End User Computing (JOEUC) 2004; 16(1): 59-72.

23. Lee Y, Kozar KA, Larsen KRT. The technology acceptance model: Past, present, and future. Communications of the Association for Information Systems 2003; 12(50): 752-780.

24.Davis FD, Bagozzi RP, Warshaw PR. Extrinsic and Intrinsic Motivation to Use Computers in the Workplace1. Journal of Applied Social Psychology 1992; 22(14): 1111-1132.

25.Zhang N, Guo X, Chen G. IDT-TAM integrated model for IT adoption. Tsinghua Science \& Technology 2008; 13(3): 306-311.

26. Tung F-C, Chang S-C, Chou C-M. An extension of trust and TAM model with IDT in the adoption of the electronic logistics information system in HIS in the medical industry. International Journal of Medical Informatics 2008; 77(5): 324-335.

27. Ardis MA, Green JA. Successful introduction of domain engineering into software development. Bell Labs Technical Journal 1998; 3(3): 10-20. 
28. Atkinson NL. Developing a questionnaire to measure perceived attributes of eHealth innovations. American Journal of Health Behavior 2007; 31(6): 612-621.

29. Völlink T, Meertens R, Midden CJ. Innovating 'diffusion of innovation'theory: Innovation characteristics and the intention of utility companies to adopt energy conservation interventions. Journal of Environmental Psychology 2002; 22(4): 333-344.

$30 . \mathrm{Wu} \mathrm{JH}$ et al. Testing the technology acceptance model for evaluating healthcare professionals' intention to use an adverse event reporting system. International Journal for Quality in Health Care 2008; 20(2): 123-129.

31. Murphy E. Issues in the adoption of broadband冈enabled learning. British journal of educational technology 2005; 36(3): 525-536.

32. Cho J, Park D, Lee HE. Cognitive factors of using health apps: Systematic analysis of relationships among health consciousness, health information orientation, eHealth literacy, and health app use efficacy. Journal of medical Internet research 2014; 16(5).

33. Conrad ED. Willingness to use IT innovations: A hybrid approach employing diffusion of innovations and technology acceptance models: Southern Illinois University Carbondale; 2009.

34. Kendall JD et al. Receptivity of Singapore's SMEs to electronic commerce adoption. The Journal of Strategic Information Systems 2001; 10(3): 223-242.

35. Greer TH, Murtaza MB. Web personalization: The impact of perceived innovation characteristics on the intention to use personalization. Journal of Computer Information Systems 2003; 43(3): 50-55.

36. Faiers A, Cook M, Neame C. Towards a contemporary approach for understanding consumer behaviour in the context of domestic energy use. Energy Policy 2007; 35(8): 4381-4390.

37. Wilkins MAJ. The health information manager as change agent in adopting electronic health record technology in hospitals: Capella University; 2009.

38. Nair SV. Benefits and security of electronic health record (EHR) use by pediatric staff: A technology acceptance model (TAM)-based quantitative study: Doctor of Philosophy thesis. CAPELLA UNIVERSITY; 2011.

39. Kowitlawakul Y. Technology acceptance model: Predicting nurses' acceptance of telemedicine technology $\left(\mathrm{eICU}^{\circledR}\right) \cdot 2008$.

40. Holden RJ, Karsh BT. The technology acceptance model: its past and its future in health care. Journal of Biomedical Informatics 2010; 43(1): 159-172.

41.Subramanian GH. A replication of perceived usefulness and perceived ease of use measurement. Decision Sciences 1994; 25(5区6): 863-874.

42.Igbaria M, Iivari J. The effects of self-efficacy on computer usage. Omega 1995; 23(6): 587-605.

43. Pai FY, Huang KI. Applying the technology acceptance model to the introduction of healthcare information systems. Technological Forecasting and Social Change 2011; 78(4): 650-660.

44. Ortega Egea JM, Román González MV. Explaining physicians' acceptance of EHCR systems: an extension of TAM with trust and risk factors. Computers in Human Behavior 2011; 27(1): 319-332.

45. Gagnon M-P et al. Systematic review of factors influencing the adoption of information and communication technologies by healthcare professionals. Journal of Medical Systems 2012; 36(1): 241-277.

46. Yu P, Li H, Gagnon M-P. Health IT acceptance factors in long-term care facilities: A cross-sectional survey. International Journal of Medical Informatics 2009; 78(4): 219-229.

47. Oh S, Ahn J, Kim B. Adoption of broadband Internet in Korea: the role of experience in building attitudes. Journal of Information Technology 2003; 18(4): 267-280.

48. Sanayei A, Ansari A, Ranjbarian B. A hybrid technology acceptance approach for using the E-CRM information system in clothing industry. International Journal of Information Science and Management (IJISM) 2012: 15-25. 